\title{
El alma de la ciudad
}

El Municipio es algo muy distinto de la mera aglomeración de seres humanos dentro de unos límites territoriales más o menos reducidos. "Término municipal" y "población" son dos factores materiales indispensables, desde luego, para iniciar la ruta hacia la meta municipal. Si a este producto se le provee de un organismo regidor, cuya obligación es crear y hacer funcionar servicios que proporcionen comodidades (vías públicas, alumbrado, abastos, transportes), seguridades (vigilanciả, guardería, defensa contra incendios), higiene (casas de baños, aguas potables, alcantarillado, cementerios), cultura (bibliotecas, enseñanza), etc., etc., tendremos ya en marcha una entidad municipal, en su acepción mecánica. No tendremos, sin embargo, un verdadero Municipio, ni en el concepto clásico español ni en el concepto moderno del mundo civilizado, porque todas estas comodidades, seguridades, necesidades, higiene, medios educativos y culturales, pueden conseguirse fuera de lo "municipal". Un Estado puede hacer llegar a todos los rincones de su territorio esos bienes. Puede hacer funcionar todos los servicios necesarios para la vida humana. Para ello le basta crear organismos burocráticos y facultativos.

Si esto es así, ¿ para qué y por qué el Municipio? Sin él se puede vivir en una calle amplia y limpia, puede uno trabajar o divertirse en plena noche, puede uno ser auxiliado en un hospital o un dispensario de urgencia, y hasta puede uno morirse 
plenamente seguro de ser alojado cómoda y decentemente en una pequeña morada... si hay dinero que impida ser arrojado a la fosa común.

De deducción en deducción iríamos a parar a una consecuencia: que el Municipio no es otra cosa que un engendro nacido de un sistema de descentralización administrattiva implantada por razones de comodidad estatal; esto es: una creación artificiosa del Estado, para ahorrarse preocupaciones e inquietudes. Claro está que, enjuiciando así, resulta que lo municipal es un desglose caprichoso de lo estatal; desglose que, por tanto, puede estar sujeto a fluctuaciones, según el criterio más o menos descentralizador del gobernante de cada momento. Este concepto municipalista lleva implícita la negación absoluta de la existencia de la "sociedad municipal" (sociedad total), de la realidad viva de que un Municipio es algo más que una porción de una Nación y algo muy distinto a un retazo de un Eistado. Los servicios municipales no serían municipales sino servicios delegados.

No basta que dentro de un edificio se sitúen unas oficinas y unos ciudadanos y que en su fachada se, coloque un rótulo para que haya Ayuntamiento o -como en la Zona de Protectorado se dice- Junta de Servicios Municipales (denominación esta última carente de enjundia y de casticismo y que, además, es incompleta e impropia, porque olvida los "bienes", los "derechos", las "acciones" y las "obras" municipales). Lo municipal tiene esencia y contenido específicos. Lo municipal no es el ramaje del árbol cuyo tronco es el Estado. Lo municipal posee vitalidad propia, savia propia, modalidades propias, medios propios, fines propios. Es un árbol cuyas raíces, tronco, ramajes, flores y frutos son y no pueden ser más que "municipales". Siguiendo el símil y considerando el Estado como un tronco, acaso, acaso, sería lo municipal la raíz de lo estatal.

Cada municipalidad tiene solera y peculiaridades, necesidades y costumbres, "hechos diferenciales", "modo de ser" y contextura. Es decir: tiene alma.

Cuando el Estado es perfecto; es decir, cuando el Estado es el organismo representativo de "una" nacionalidad, se da un 
fenómeno paradójico: fọrma un todo compacto, homogéneo, apretado, único, estando integrado por un conjunto rabiosamente heterogéneo de bien distintas municipalidades. ¿Puede alguien negar la dispar fisonomía que ofrecen el Municipio netamente urbano y el rural? ¿Cabe ignorar que, por ejemplo, Barcelona, Sevilla y San Sebastián poseen caracteres bien definidos y personalidad distinta? ¿Puede olvidarse que la municipalidad gallega constituye una "sociedad" diferente del Municipio rural murciano? Es que el Municipio tiene un contenido inalienable: tiene alma. No es una parte de un todo. Es un todo. $Y$ es así necesariamente, porque el proceso formativo de la colectividad no ha sido, ni es, ni será de arriba hacia abajo, sino de abajo arriba. El espíritu de la nacionalidad está formado y. nutrido por el. alma de la municipalidad. Sabemos la diferencia que en química tiene la mezcla de la combinación. En la primera, los elementos formativos del conjunto conservan sus primitivos caracteres, y en la segunda desaparecen. Pues bien: en ese proceso de formación colectiva las municipalidades, distintas esencialmente, poseen a la vez puntos de coincidencia que unidos hacen el milagro del sentimiento de la nacionalidad. En lo humano se verifican los dos fenómenos: "mezcla" y "combinación": mezcla de lo diferente, combinación de lo uniforme. Aquello es el todo municipal, esto el todo nacional.

El Municipio, en Marruecos, en este aspecto, se halla en período de gestación; y ésta es penosa porque dentro de cada aglomerado de población hay multiplicidad de razası y, por tanto, de caracteres, de sentimiento de la necesidad, de mentalidades, de costumbres; y, además, un porcentaje enorme de eternos forasteros que sin poder llamarse población flotante, carecen de arraigo y no son factores propicios a contribuir a la forjación del "espíritu de la ciudad". Ejemplo de primerísima línea, Tánger.

Fijando nuestra atención en la Zona de Protectorado español, se da con muy acusado trazo lo musulmán, lo español, lo israelita y, finalmente, lo uindefinido». Esto último, formado por un abigarrado conjunto, poco numeroso pero muy vario, que sólo tiene un punto de coincidencia, negativo: desconocer 
la "convivencia" municipal en cuanto no conviene (esto es, lo que cuesta dinero), y exigirla en cuanto beneficia a "uno". Lo que tiene raíces hondas, que es lo marroquí (musulmán e israelita) y lo español, va, paso a paso, lentamente, dibujando la personalidad y la espiritualidad municipalista. Lo otro es un lastre, asaz pesado, que la entorpece.

No se logra, no, el perfeccionamiento municipalista hispano-marroquí dando o quitando servicios, ni atribuyendo, ni sumando, ni restando competencia municipal, porque ésta es inalienable de jure en Marruecos, en España y en Norteamérica. Esto se conseguirá solamente prestando ayuda a esa fuerza inmaterial que va formando lo que es indispensable para que la masa, la materia, la energía se vivifiquen: el alma de la ciudad. Ese espíritu es formación, es obra de España, y, de persistir cual' es de esperar, el propósito, la mayor y más legítima gloria de España como nación protectora.

\section{I}

En cuanto a su fecha es relativamente moderna la vigente legislación en la Zona de Protectorado, en materia municipal.

Se denomina Reglamento Municipal para la Zona de Protectorado de España en Marruecos, y no fué aprobado por Dahir sino mediante una Ordenanza de 19 de agosto de 1942. Con ser mucho más "municipalista" que la de la Zona francesa, necesita de amplia reforma. $Y$ ésta viene siendo objeto de un profundo estudio que se inició hace dos años y medio.

El actual Reglamento establece una distinción entre los municipios hispano-marroquíes: mayores (de más de 2.000 habitantes de hecho) y menares (los que no alcanzan dicho número). No atinamos a comprender cuál fué el pensamiento del legislador, pues aunque el organismo representativo se llama en los primeros Junta de Servicios Municipales, y en los.segundos Junita Local Consultiva, una y otra están revestidas de igual personalidad, competencia y atribuciones similares, y obligaciones y responsabilidades idénticas. La única diferencia entre una $\mathrm{y}$ otra se encuentra en los elementos que las constituyen. Es 
decir: son municipios mayores y tienen un órgano representativo, Junta Municipal, los aglomerados de población mayor; y son menores y están regidos por una Junta Local Consultiva los poblados más pequeños. La clasificación no parece estar justificada.

Carece de contenido sustantivo legal el Municipio, toda vez que no se traslada a la regla jurídica, lo que fué su alma creadora y vivificadora. Si el Municipio es una sociedad "natural", anterior a la ley, debe recoger ésta ese contenido sustantivo "natural" que le dió vida, impulso, ímpetu; esto es: que le hizo necesario. No se trata de una ficción legalista, sino algo muy superior a la ley positiva. Una prueba: creado el Municipio de Torres de Alcalá, antes de que "cuajara», naturalmente, hubo de ser suprimido. Otra prueba: ¿ por qué no son ya municipios los poblados de Dar Chaui y R'Gaia, por ejemplo? ¿Por qué no se han formado términos municipales ni se han constituído municipios en las cábilas? La respuesta es sencilla y fácil: porque no hay vida municipal, contenido municipal, "alma», en fin que "cuaje" esa sociedad total, de peculiaridades locales, de exigencias locales, de organización, administración y gobierno local. El Municipio que no nace por sí mismo y, sin embargo, se le da existencia jurídica, no es otra cosa que un engendro, una ficción.

Examinando el fenómeno al revés, la sociedad local natural necesita de la ley ese pleno reconocimiento de su esencia y vitalidad. Una regla jurídica que recoja estos principios y encauce esa multiplicidad de anhelos, contribuirá indudablemente a que el desenvolvimiento de lo municipal tenga prestancia, tenga lozanía, y, lejos de ahogarse, aumente su energía, se desarrolle espléndidamente. Lo jurídico es el marco, solamente el marco. Nadie pretenderá que una maravillosa obra de arte pictórica tenga un marco pobre, inadecuado. A nadie puede ocurrírsele encuadrar esa obra dentro de un marco de menores dimensiones a las de ella, recortándola.

Una vez -allá en mi tierra murciana - hubo un hombre que, cargado de riqueza, quiso tener en su hogar una numerosa biblioteca. De estas cosas no entendía, pero quería tener muchos 
libros para demostrar a sus visitantes que él era un intelectual. Encargó unos magníficos armarios y compró libros y más libros : y, cuando llegó el momento de instalar éstos en aquéllos, no cabían en los espacios previstos por el mueblista. En lugar de que éste rectificase las alturas, al buen hombre no se le ocurrió otra solución que enviar todos los libros a la "guillotina", y... fueron "recortados", quitándoles lo que les sobraba para que cupiesen en los armarios. No es cuento, conste.

El Municipio tiene un contenido inalienable; unos fines específicos, privativamente suyos; una fisonomía acrisolada por. la especialísima manera de ser de la colectividad local que le engendró, manera de ser que es varia en cuanto a peculiaridades y una en cuanto a raíces y fundamento. Ló uniforme debe recogerlo la lèy; lo vario debe admitirlo la flexibilidad de la ley. Lo básico y fundamental debe respetarlo y encauzarlo la ley.

No conviene, no, "recortar" ni deformar ese contenido, ni desvirtuar esa esencia. Ello fuera tanto como hacer lo que el murciano de los libros...

\section{I I}

Define el Reglamento municipal de la Zona de Protectorado la competencia de los municipios, diciendo en su artículo 54: «Es de la exclusiva competencia (de los municipios), tan sólo subordinada a la observancia de las leyes generales del Protectorado de España en Marruecos, el gobierno, fomento, dirección y administración de los intereses peculiares de las poblaciones, sean de índole moral o material".

La subordinación que establece en eli artículo siguiente (55) de las entidades municipales respecto de un Centro superior esitatal (llamado Inspección de Entidades Municipales), al exigir que determinados acuerdos municipales sean censurados previamente por ese Organismo supermunicipal para que adquieran eficacia legal, no afecta al fondo del problema ni roza R. tema de este trabajo. La existencia de Centros superiores de asesoramiento e inspección es útil ; y, en este aspecto, plausible la instauración de ese Organismo fiscalizador. 
Ahora bien: esa definición de la competencia municipal, por sí sola, es algo abstracto, impreciso. ¿Cuáles son los intereses peculiares de las poblaciones? ¿Hasta dónde alcanza en cuanto a tales intereses la esfera de la jurisidicción municipal? No se dice. No se sabe. El precepto copiado parece que debiera desmenuzarse en otros enumerativos que concretasen específicamente lo que dice en términos genéricos ese artículo 54. Sorprende no hallarlos. Solamente se especifican las obligaciones de las Juntas Municipales, mas no sus funciones y atribuciones. Esta laguna tan fundamental será seguramente salvada en la anunciada reforma legislativa; y, con ello, además de elaborar fácilmente el marco jurídico adecuado al "alma municipal hispano-marroquí", quedarán suprimidos los motivos de confusionismo entre la Administración del Estado y la municipal.

El tránsito rodado - por ejemplo- dentro de las poblaciones, es de ordenación municipal; $y$ ha tenido que decírselo a la Administración municipal el Reglamento aprobado por Dahir de 30 de abril de 1946, sobre circulación y transportes por carretera. Si la competencia municipal se halla diluída -y no por cierto en su totalidad- entre recovecos de disposiciones legales reguladoras de servicios estatales, las cuales, como es lógico, se dictan siempre con el pensamiento puesto íntegramente al' servicio del bien general, del interés general, pero olvidando frecuentemente si ese interés general corresponde o no al ojo vigilante y al celo inquieto del Organismo representativo de la ciudad, además de no reflejarse èn su lugar propio, tiene el grave inconveniente de estar interpretada fraccionadamente, faltando la unidad de pensamiento, de concepto, de criterio.

Pero es que tal sistema trae otras consecuencias. Veámoslo. Un día se piensa que en los principales municipios, por circunstancias diversas, se observa que los servicios sanitarios municipales no están debidamente atendidos; y, entonces, para remediar el mal, se dice a la Administración municipal: "Os quitamos estos servicios - que son netamente municipales-, los vais a seguir pagando, y el Estado asume su organización, dirección, administración, etc., etc.". ¿Por qué ? ¿Es que la Administración municipal puede fracasar? Pensemos que la cir- 
cunstancia de que un Ministro del Ejército realice una labor desacertada no debe tener como remedio la desaparición del Ministerio. El Ministerio, el sistema, el Organismo, no, no ha fracasado. Ha fracasado el Ministro. Un Alcalde o un Ayuntamiento o una Diputación provincial pueden hacer una labor sanitaria nula, y por esto no debe desaparecer la Sanidad municipal ni la Sanidad provincial. Se ataca y destruye o adultera la esencia; y, con ello no se da con la solución. En el caso que hemos señalado como ejemplo, la Sanidad municipal no puede despojarse de la Autoridad municipal que es la que "de cerca" ha de velar por el perfeccionamiento higiénico-sanitario del $\mathrm{Mu}$ nicipio. La higiene y habitabilidad de viviendas, industrias y locales mercantiles, es función municipal; la desinfección y desinsectación, es servicio municipal; la profilaxis -en materia de vacunaciones, saneamientos, desecaciones de terrenos pantanosos e insalubres-, es misión municipal. Quemar una partitura musical porque lọs músicos son malos y la interpretan mal, es un desatino. Quitar una función privativa y peculiar del Municipio a sus rectores -en vez de quitar a éstos y poner otros-, no es medida eficaz. Así se "mata el alma de la ciudad".

¿Qué más da que un servicio esté en manos estatales o en manos de quienes tienen a su cargo los intereses de la ciudad? No. No es así; no puede ser así. Las Delegaciones de Servicios estatales, centros perfectamente organizados, servidos por funcionarios supercapacitados, pueden funcionar maravillosamente... para cumplir su cometido, y nada más. Eso no es nada parecido a "lo local». ¿Por qué un Ayuntamiento o una Junta de Servicios Municipales es algo muy distinto a una oficina pública? ¿Por qué un Organismo municipal no está servido exclusivamente por "funcionarios de plantilla"? La respuesta es muy sencilla: porque esos funcionarios, maravillosos pilares de la vida municipal, hombres de carrera brillante muchos; de ellos, que cumplen con su deber estupendamente, son absolutamente necesario's; tan necesarios, que sin ellos no hay nada que hacer. Pero no bastan. Ellos van a la Administración municipal a trabajar, a seguir su carrera, a defender los intereses municipales, a cooperar a la brillantez de la labor de con- 
junto; a "ejecutar" los planes de embellecimiento, de mejoramiento, de resurgimiento, de la ciudad; pero ellos no llevan ni pueden llevar a la Casa de la ciudad el aliento, el contenido espiritual, las esencias y los anhelos, el alma, en fin, de 'a sociedad local llamada Municipio. Todo esto, nada más y nada menos, es lo que a esa Casa que es tan del pueblo llevan los hombres del pueblo: los gestores, llámense concejales o denomínense vocales; $\mathrm{y}$, sobre todo, ese hombre, también del pueblo, que es la castiza, legendaria y gloriosa figura del Alcalde.

Andrés Hernández Anrich 